\title{
EQUAÇÕES INDIVIDUAIS E DETERMINAÇÃO DE CLASSES DE CRESCIMEN- TO PARA Nectandra grandiflora NEES A PARTIR DE DADOS DE ANÁLISE DE TRONCO
}

\section{INDIVIDUAL-LEVEL EQUATIONS AND GROWTH CLASSES FOR Nectandra grandiflora NEES FROM STEM ANALYSIS}

\author{
Carlos Roberto SANQUETTA ${ }^{1}$ \\ Saulo Henrique WEBER ${ }^{2}$ \\ Fernando FORMAGINI ${ }^{3}$ \\ Laércio Silveira BARBEIRO ${ }^{4}$ \\ Gislaine VIEIRA ${ }^{5}$
}

\begin{abstract}
RESUMO
A espécie Nectandra grandiflora tem ampla distribuição, desde o Rio Grande do Sul até Minas Gerais e tem especial importância em função de seu potencial para a produção de não madeiráveis. O objetivo do presente trabalho foi estabelecer curvas de crescimento para a espécie Nectandra grandiflora por meio de análise de tronco, bem como determinar classes de crescimento. Foram ajustados, utilizando-se o método de Marquardt, os modelos de Gompertz, Logística, de Chapman-Richards, Bertalanffy, Korf e Weibull, sendo o último o que o que melhor aderiu aos dados. Foram determinadas funções para estimar o diâmetro da base em função do DAP e o diâmetro da base com casca em função do diâmetro da base sem casca. Observou-se que os anéis de crescimento dessa espécie são visíveis. As classes de crescimento foram teoricamente relacionadas com a cobertura do dossel (pleno sol, parcialmente sombreada e sombreada). A espécie é bastante tolerante à sombra, mantendo níveis de crescimento estáveis quando mantidas as condições de sombra, e acelerando o crescimento quando alcança o dossel superior.

Palavras-chave: modelos de crescimento; floresta ombrófila mista; posição sociológica.
\end{abstract}

\begin{abstract}
The species Nectandra grandiflora is widely distributed from the Rio Grande do Sul to Minas Gerais States and have special importance due to its potential as non-woody products. The objective of this study was to establish growth rates curves for Nectandra grandiflora through stem analysis, as well as to determine its growth rates. The following models were adjusted using the Marquardt method: Gompertz, Logistics, Chapman-Richards, Bertalanffy, Korf and Weibull, and the last one resulted in the best fit. It was established functions to estimate the base diameter as function of the DBH and the base diameter with bark as function of base diameter without bark. It was observed that the growth rings of this species were visible. The growth classes were theoretically related to the canopy coverage (open, partially shaded and shaded canopy). The species is very shade-tolerant, maintaining its growth rates when kept under shaded conditions, and accelerating its growth when achieved the upper canopy.

Key-words: models; mixed ombrophilous forest; growth sites.
\end{abstract}

\footnotetext{
${ }^{1}$ Engenheiro Florestal, Ph.D., Departamento de Ciências Florestais da Universidade Federal do Paraná, Bolsista PQ -1C do CNPq, Laboratório do Inventário Florestal, Av. Lothário Meissner, 632, Jardim Botânico, 80.210-170 Curitiba, Paraná, Brasil. E-mail: sanquetta@ufpr.br. Autor para correspondência

${ }^{2}$ Matemático, MSc., Doutorando em Engenharia Florestal na Universidade Federal do Paraná, Bolsista do CNPq. Rua Fátima Bark, 405 81.130-270, Capão Raso, Curitiba, Paraná, Brasil. E-mail: sauloweber@gmail.com

${ }^{3}$ Acadêmico de Engenharia Florestal da UFPR, Bolsista Iniciação Cientifica do CNPq, R. Marília de Lacerda C., 261, $82900-365$ Curitiba Paraná, Brasil. E-mail: fformagini@yahoo.com.br;

${ }^{4}$ Acadêmico de Engenharia Florestal da Universidade Federal do Paraná, Bolsista de Apoio Técnico do CNPq, Av. Lothário Meissner, 632 Jardim Botânico, 80.210-170 Curitiba, Paraná, Brasil. E-mail: laeguitar@hotmail.com

${ }^{5}$ Acadêmica de Farmácia e Bioquímica da Pontifícia Universidade Católica do Paraná (PUC-PR), Bolsista de Apoio Técnico do CNPq, Av. Lothário Meissner, 632, Jardim Botânico, 80.210-170 Curitiba, Paraná, Brasil. E-mail: gigi_farma@hotmail.com
} 
SANQUETTA, C.R. et al. Equações individuais e determinação de classes...

\section{INTRODUÇÃO}

A floresta ombrófila mista, também conhecida como floresta com araucária, já cobriu cerca de $58 \%$ do Paraná. Entretanto, hoje os remanescentes originais cobrem não mais que 1,3\% do Estado (Sanquetta \& Mattei, 2006), dado que reforça a grande necessidade de conservação deste ecossistema. Para preservar essa vegetação tão singular, uma das premissas mais básicas é que se conheçam melhor as suas características, tais como florística, estrutura e função (Schaaf, 2001).

A Nectandra grandiflora Nees, também conhecida como canela-amarela, pertence à família das Lauráceas e ocorre do estado de Minas Gerais ao Rio Grande do Sul, na Floresta Ombrófila Mista, em altitudes entre 600 e 1300 m. Essa espécie é particularmente freqüente no Segundo Planalto Paranaense (Lorenzi, 1998), e segundo Sanquetta et al. (2002) tem elevados valores de importância na estrutura fitossociológica na floresta com araucária da região de São João do Triunfo, sendo a segunda mais abundante (61 ind ha $\left.{ }^{-1}\right)$ e mais freqüente $(37,14 \%)$. Quanto à importância econômica, sua madeira pode ser empregada em construção civil, mas seu grande potencial está nos produtos não madeiráveis, como os fito-fármacos, por exemplo.

A modelagem do crescimento de um ser vivo permite explicar e predizer o comportamento de uma de suas dimensões no decorrer do tempo, sendo um requisito fundamental para se desenvolver qualquer tipo de atividade, seja de exploração ou conservação. Porém infelizmente não há muita informação nem modelos de crescimento para a maioria das espécies da tão variada flora brasileira - como Nectandra grandiflora - particularmente para árvores crescendo em diferentes condições sociológicas.

Vaccaro et al. (2003), estudando o incremento em área basal de árvores de uma Floresta Estacional Semidecidual em três fases sucessionais, concluíram que não houve perda significativa de precisão, quando comparadas equações gerais e específicas para cada estágio sucessional.

O objetivo deste trabalho foi estabelecer curvas do crescimento em diâmetro de Nectandra grandiflora, baseando-se em análise de tronco, considerando diferentes ritmos de crescimento correlacionados com as condições ambientais das árvores (posição sociológica), bem como estabelecer essas classes.

\section{MATERIAL E MÉTODOS}

\section{Descrição da área de estudo}

Este estudo foi realizado no município de São João do Triunfo, Região Centro-Sul do Paraná. A altitude do local é de $780 \mathrm{~m}$, com latitude Sul de 25'34'18" e longitude Oeste de 5005'56" de Greenwich (Sanquetta et al., 2002).

Segundo a classificação de Köeppen, o clima da região é tipo Cfb - clima temperado sempre úmido com temperatura média inferior a 22
${ }^{\circ} \mathrm{C}$ durante o mês mais quente, sem estação seca, com verões frescos e mais de cinco geadas noturnas por ano (Sanquetta et al., 2002).

De acordo com Sanquetta et al (2002), o solo predominante na floresta é do tipo Cambissolo Háplico Alumínico.

\section{Preparação das amostras para as análises}

As amostras deste estudo foram coletadas no primeiro trimestre do ano de 2007 e fazem parte do Programa de Pesquisas Ecológicas de Longa Duração, Site 9 (PELD).

Foram abatidas 30 árvores da espécie, representando as várias classes de DAP, que tiveram seções transversais de seus troncos amostradas, extraindo-se dois discos de cada árvore, um na base e outro à altura do peito. Após a identificação, estes discos foram devidamente secos e lixados, e então levados até o Laboratório de Inventário Florestal da Universidade Federal do Paraná, onde foram submetidos à análise. Esta consistiu em traçar duas retas perpendiculares em cada disco, cuja interseção coincidiu com o centro do disco, sendo a primeira reta a $45^{\circ}$ do maior raio encontrado em cada disco. Assim foram determinados os quatros raios adequados para medição, em cada disco, viabilizando a realização da leitura dos anéis. Com escalímetro, lupa e lapiseira 0,5 e $0,3 \mathrm{~mm}$ foram identificados e medidos os anéis verdadeiros em cada raio, bem como a espessura de casca. Finalmente, os dados foram digitados, trabalhando-se com a média dos anéis de cada disco.

Os modelos utilizados neste estudo foram Gompertz (Gompertz, 1825), Logística (Nelder, 1961), Chapman-Richards (Richards, 1959), Bertalanffy (Bertalanffy, 1957), Weibull (Weibull, 1951) e Korf (Korf, 1939). Estes foram ajustados pelo método de Marquardt, com o auxílio do Software Table Curve 2d. A maioria dos algoritmos para estimar equações não lineares pelo método de mínimos quadrados centra-se em uma de duas aproximações. Por um lado, o modelo pode ser expandido como uma série de Taylor e as correções dos coeficientes calculadas a cada iteração, na suposição de linearidades locais. Por outro lado, diversas modificações do método gradiente estão sendo usadas. O método de Marquardt utiliza o método de máxima verossimilhança, que executa uma ótima interpolação entre o método da série de Taylor e o gradiente (Marquardt, 1963).

Os modelos ajustados foram comparados por meio do coeficiente de determinação múltiplo ajustado e do erro padrão da estimativa recalculado em percentagem. $O$ coeficiente de determinação múltiplo é a razão entre a soma dos quadrados da regressão e a soma dos quadrados totais, de acordo com a Equação 1:

$$
\mathrm{R}^{2}=\frac{\text { SQregressão }}{\mathrm{SQT}}
$$

(Equação 1) 
O coeficiente de determinação múltiplo ajustado é a correção do $R^{2}$ para modelos com diferentes números de parâmetros (Equação 2), em que $n$ é o número de dados e $p$ o número de parâmetros estimados pelo modelo em questão.

$$
\mathrm{R}_{\text {ajustado }}^{2}=1-\left\{\left(1-\mathrm{R}^{2}\right) \cdot\left(\frac{\mathrm{n}-1}{\mathrm{n}-\mathrm{p}}\right)\right\}
$$

(Equação 2)

O erro padrão da estimativa recalculado é a raiz quadrada do quociente entre: 1) o somatório do quadrado da diferença entre os valores observados e os estimados, e 2) a diferença entre o número de dados e o número de parâmetros estimados pelo modelo em questão, conforme Equação 3, em que $y_{i}$ é freqüência observada e $\hat{y}_{i}$ é a freqüência estimada pelos modelos.

$$
S_{y x} \text { recalculad } o=\sqrt{\frac{\sum_{i=1}^{n}\left(y_{i}-\hat{y}_{i}\right)^{2}}{n-p}}
$$

(Equação 3)
As curvas anamórficas foram posteriormente encontradas, baseadas no modelo escolhido, e estas são definidas como as que possuem uma proporcionalidade no desenvolvimento entre as curvas que compõem a família de equações (Scolforo, 1993). Essas curvas são comumente usadas para representar curvas de índice de sítio. No presente estudo não convém atribuir essa designação, uma vez que não há como associar o crescimento dessa espécie em seu ambiente natural a sítios de produção, mas sim com as condições ambientais que favoreçam seu desenvolvimento.

\section{RESULTADOS E DISCUSSÃO}

\section{Formação e padrão dos anéis de crescimento}

Nectandra grandiflora apresentou anéis de crescimento visíveis, permitindo a análise de tronco, apesar de a forma dos discos não ser circular (Figura 1), pelo contrário, a maioria das árvores apresentou seção elíptica e com reentrâncias. Uma vez que os anéis se mostraram visíveis, foi, assim, possível mensurar os diâmetros nas diferentes idades e determinar os seus incrementos anuais.
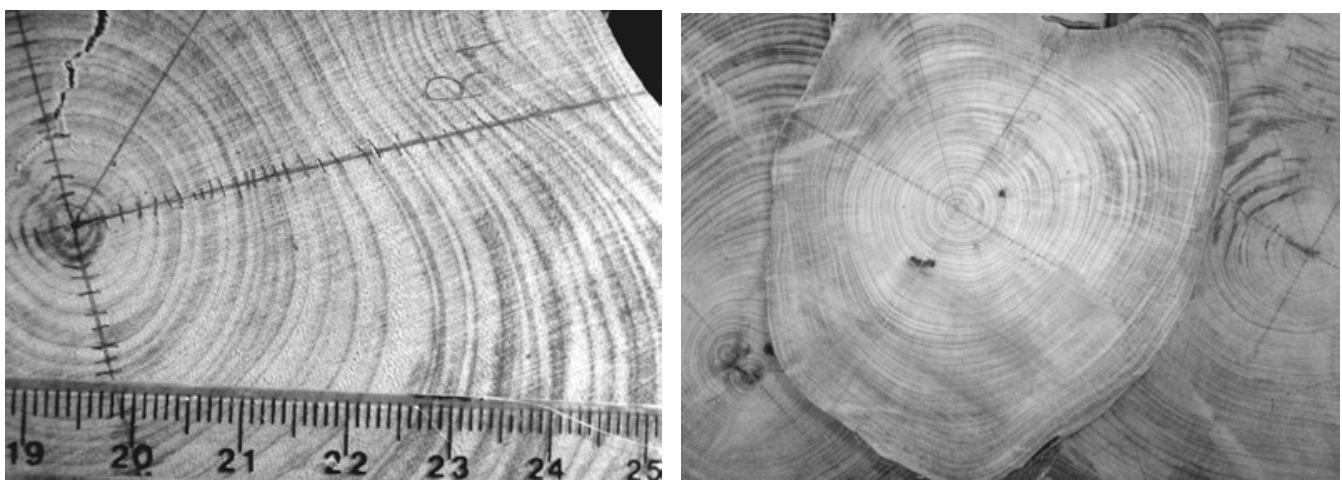

FIGURA 1 - Visibilidade dos anéis de crescimento no discos da base (direita) e à altura do peito (esquerda)

O maior diâmetro da base sem casca observado foi de $273,00 \mathrm{~mm}$, correspondente a um diâmetro de 283,16 mm com casca. Esses diâmetros basais correspondem, respectivamente, a 266,75 e 276,73 mm em DAP. A idade das árvores variou entre 16 e 71 anos.

As plantas levaram, em média, aproximadamente quatro anos para atingir 1,3 m (altura do peito), de acordo com os anéis de crescimento. A média dos DAPs (com casca) foi de $134,04 \mathrm{~mm}$, com $50,31 \mathrm{~mm}$ de desvio padrão. O incremento médio anual em DAP (IMA) variou entre 1,84 e $5,27 \mathrm{~mm}^{-1}(2,78 \pm 0,76 \mathrm{~mm})$. Figueiredo Filho et al. (2003) observaram um crescimento anual em diâmetro entre 2,42 e 3,14 mm, em seu estudo realizado na mesma área, com cintas dendrométricas em 19 indivíduos, valores próximos aos encontrados também por Schaaf et al. (2005), ou seja, $3,1 \mathrm{~mm}$. Em estudo realizado na Floresta Nacional de Irati, PR, Figueiredo Filho et al. (2006) observaram incrementos de 0,87 a $1,81 \mathrm{~mm}^{2} \mathrm{ano}^{-1}$. Isso mostra que essa espécie possui taxas de crescimento variáveis, principalmente em função do ambiente em que cresce.

\section{Reconstrução do crescimento em DAP com casca}

Foi procedida uma regressão linear com os dados de 28 árvores para estimar o diâmetro da base das árvores 7 e 19, uma vez que essas informações não constavam no banco de dados. 0 resultado do ajuste foi uma equação linear (Equação 4) com $\mathrm{R}^{2}$ igual a 0,9689 (Figura 2), em que $D B_{s c}$ é o diâmetro sem casca e $D P_{s c}$ é o diâmetro à altura do peito sem casca. A relação de mostrou muito estável e, por conseguinte, o ajuste foi satisfatório.

$$
\mathrm{DB}_{\mathrm{sC}}=1,0246 \cdot \mathrm{DAP}_{\mathrm{SC}}+15,506
$$

(Equação 4) 
SANQUETTA, C.R. et al. Equações individuais e determinação de classes...

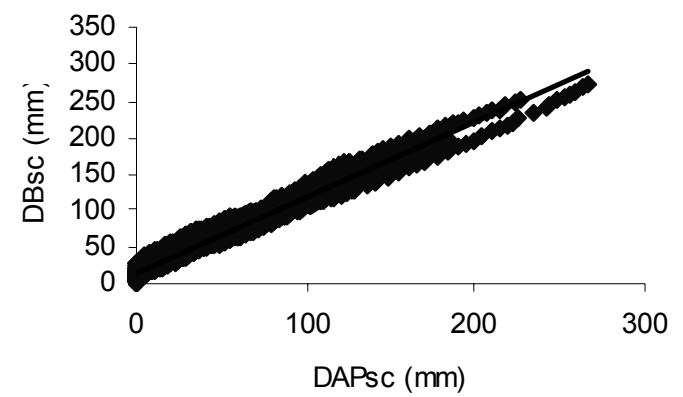

FIGURA 2 - Ajuste de equação linear aos dados de diâmetro da base sem casca (DBsc) em função do diâmetro a altura do peito sem casca(DAPsc)

Utilizando-se os dados dos diâmetros com $\left(D_{c c}\right)$ e sem casca $\left(D_{s c}\right)$ foi possível estabelecer uma relação direta entre essas variáveis, com $R^{2}$ de 0,9904 (Equação 5, Figura 3). Isso possibilitou estimar o diâmetro com casca de acordo com os anéis de crescimento, ou seja, em função da idade (Figura 4). O diâmetro da base sem casca variou entre 86 e $273 \mathrm{~mm}(144 \pm 52 \mathrm{~mm})$, enquanto que o com casca ficou entre 88 e $283 \mathrm{~mm}(150 \pm 54 \mathrm{~mm})$. A diferença entre os diâmetros da base esteve entre 2 e $28 \mathrm{~mm}(6 \pm 5 \mathrm{~mm})$.

$$
\mathrm{DB}_{\mathrm{CC}}=1,0287 \mathrm{DB}{ }_{\mathrm{sc}}+2,3279
$$

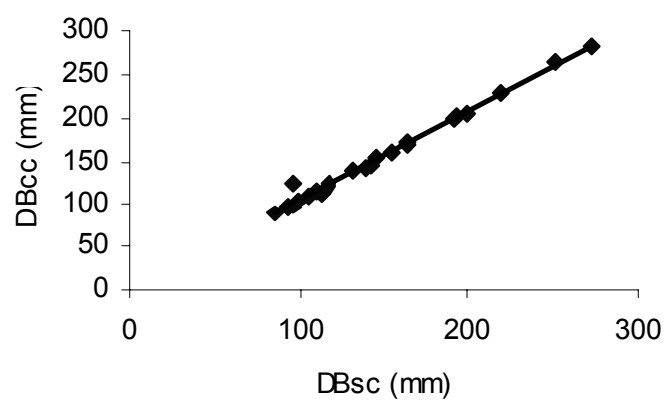

FIGURA 3 - Ajuste de equação linear aos dados de diâmetro da base com casca (DBcc) em função do diâmetro sem casca(DBsc)

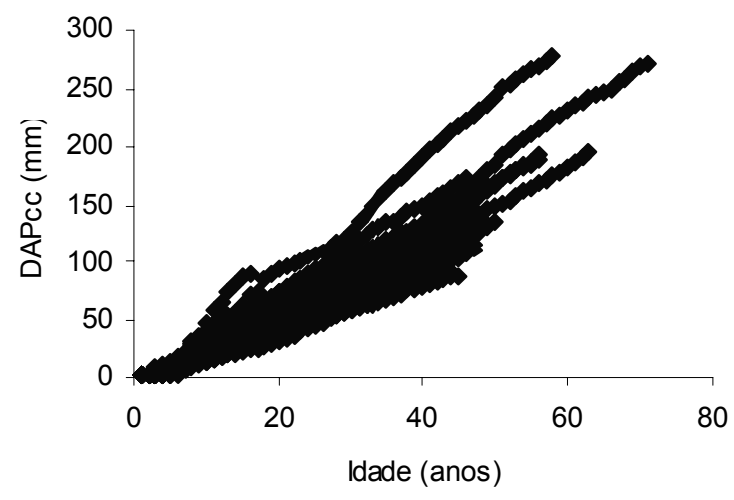

FIGURA 4 - Dados do diâmetro à altura do peito com casca (DAPcc) em função da idade da árvore

Observa-se pela Figura 4 que a relação entre idade e DAP é retratada por uma nuvem de pontos caracterizada por grande dispersão. Isso decorre da variação ambiental entre árvores, possivelmente na sua condição de luminosidade, conforme será abordado mais adiante. 
SANQUETTA, C.R. et al. Equações individuais e determinação de classes...

Ajuste dos modelos de crescimento

Foram ajustados aos dados de crescimento os modelos de Gompertz, Logística, Chapman-Richards, Bertalanffy, Weibull e Korf (Figura 5), cujos resultados estão apresentados na Tabela 1. Esses modelos possuem teoricamente os atributos clássicos dos modelos biológicos, ou seja, partem da origem ( $Y=0$ quando $X=0)$, possuem pontos de inflexão correspondentes às fases do crescimento (juvenil, madura e senil) e tendem a um valor assintótico em $\mathrm{Y}$, quando $\mathrm{X}$ tende ao infinito.

TABELA 1 - Modelos de crescimento ajustados para este trabalho, usando a idade da árvore como variável independente e o diâmetro como variável dependente, além dos coeficientes e parâmetros estatísticos encontrados para cada um deles.

\begin{tabular}{lcccccc}
\hline Função & Forma matemática & $\mathrm{a}$ & $\mathrm{b}$ & $\mathrm{c}$ & $\mathrm{R}^{2}$ & Syx \\
\hline Gompertz & $\mathrm{f}(\mathrm{x})=\mathrm{a} \cdot \mathrm{e}^{-\mathrm{b} \cdot \mathrm{e}^{-\mathrm{c} \cdot \mathrm{x}}}$ & 536,65 & 4,0347 & 0,02 & 0,88 & 17,99 \\
\hline Logística & $\mathrm{f}(\mathrm{x})=\frac{\mathrm{a}}{\left(1-\mathrm{c} \cdot \mathrm{e}^{-\mathrm{b} \cdot \mathrm{x}}\right)}$ & 312,49 & 0,0649 & $-21,72$ & 0,88 & 18,46 \\
\hline Chapman-Richards & $\mathrm{f}(\mathrm{x})=\mathrm{a}\left(1-\mathrm{e}^{-\mathrm{b} \cdot \mathrm{x}}\right)^{\mathrm{c}}$ & 3332,77 & 0,0025 & 1,41 & 0,89 & 17,88 \\
\hline Bertalanffy & $\mathrm{f}(\mathrm{x})=\mathrm{a}\left(1-\mathrm{e}^{-\mathrm{b} \cdot \mathrm{x}}\right)^{3}$ & 270,06 & 0,0373 & & 0,85 & 20,43 \\
\hline Weibull & $\mathrm{f}(\mathrm{x})=\mathrm{a}\left(1-\mathrm{e}^{-\mathrm{b} \cdot \mathrm{x}^{\mathrm{c}}}\right)$ & 2673,59 & 0,0003 & 1,37 & 0,89 & 17,84 \\
\hline Korf & $\mathrm{f}(\mathrm{x})=\mathrm{a} \cdot \mathrm{e}^{-\mathrm{b} \cdot \mathrm{x}^{-\mathrm{c}}}$ & $23.311,23$ & 12,8084 & 0,24 & 0,88 & 18,42 \\
\hline
\end{tabular}

Onde: $f(x)=\operatorname{DAP}(\mathrm{cm}) ; x=$ idade (anos), Syx= erro padrão da estimativa.
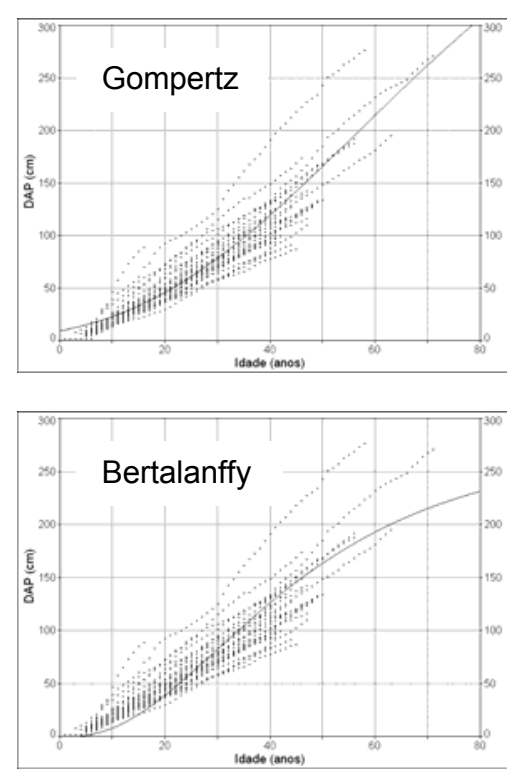
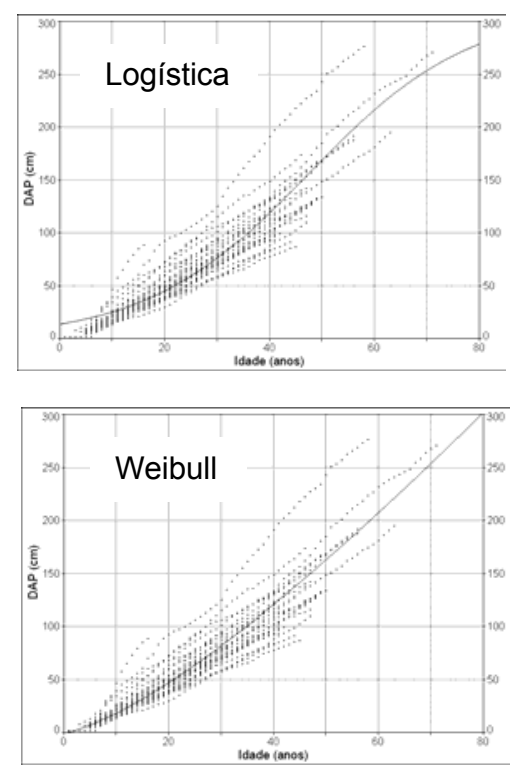
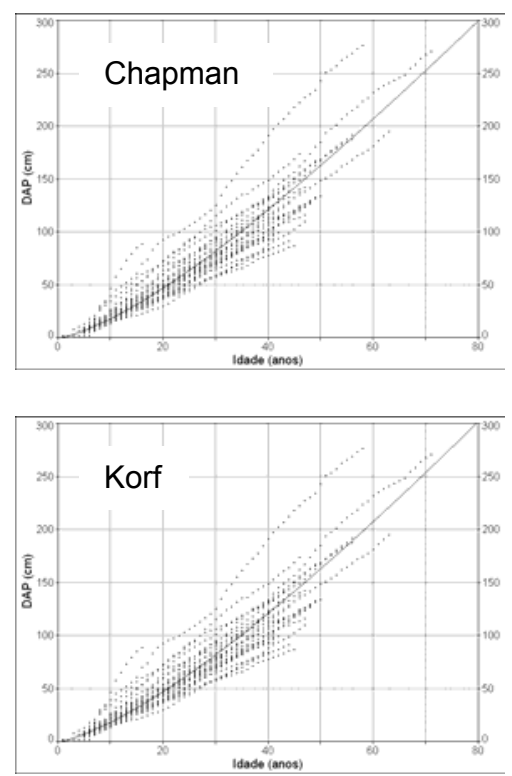

FIGURA 5 - Modelos de Gompertz, Logística, Chapman-Richards, Bertalanffy, Weibull e Korf ajustados aos dados de crescimento em função do tempo

O ajuste dos modelos revelou que Gompertz e Logística resultaram num ajuste insatisfatório nas classes iniciais, superestimando os DAPs, enquanto que o de Bertalanffy os subestima. As equações de Chapman-Richards, Korf e Weibull três parâmetros resultaram satisfatórias e, entre elas, pode-se dizer que Weibull foi melhor porque apresentou maior $\mathrm{R}^{2}$ ajustado e menor Syx.

Percebe-se, a partir das curvas individuais de crescimento (Figura 4), que a espécie apresenta grandes variações em termos de desenvolvimento na floresta. Segundo Tonini et al. (2003), a luminosidade na copa é um dos fatores mais 
SANQUETTA, C.R. et al. Equações individuais e determinação de classes...

relevantes, dentre os diversos que contribuem para um comportamento variado das taxas de crescimento entre indivíduos da mesma espécie. Tal afirmação pode ser aplicada também neste caso, pois a área de estudo é pequena ( 31,5 ha) e supostamente homogênea em termos de solos, sendo assim menos provável a influência dos fatores edáficos e genéticos. Portanto, atribui-se essa variação de crescimento ao fator luminosidade. Com base nessa suposição foram desenvolvidas curvas de crescimento em separado para as diferentes classes de iluminação de copa.

Para a confecção das curvas de crescimento por classe de iluminação de copa foram traçadas linhas anamórficas, utilizando-se como idade de referência 41 anos, pois 25 dos 30 indivíduos amostrados (83\%) estavam abaixo dessa faixa etária (Figura 6). Ressalta-se que os intervalos entre as linhas anamórficas determinam as classes de crescimento das árvores.

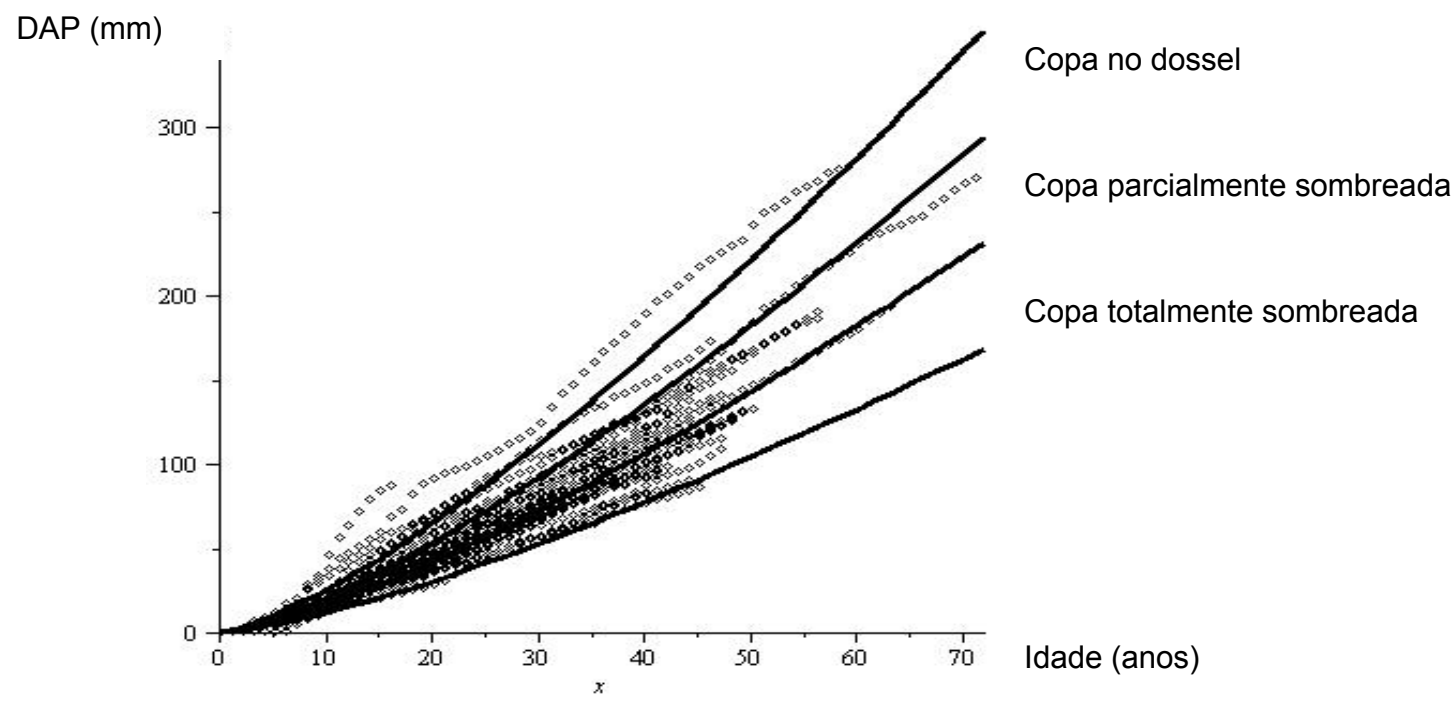

FIGURA 6 - Curvas anamórficas da equação de Weibull

As árvores analisadas apresentaram crescimentos variáveis, conforme as curvas apresentadas na Figura 6. Como mencionado anteriormente, esse crescimento variável provavelmente está relacionado com a disponibilidade de luz na parte fotossinteticamente ativas das árvores. Com base nestas suposições e nas distribuições ajustadas, foram determinadas três classes de crescimento:

Classe I: copa em pleno sol (árvores presentes em áreas onde houve ocorrência de dinâmica de clareira ou áreas de bordadura);

Classe II: copa parcialmente Sombreada (árvores presentes em áreas com sombreamento parcial ou indireto); e

Classe III: copa sombreada (árvores sob cobertura, sem iluminação direta).

Adicionalmente foram estabelecidas classes suplementares para abranger as árvores com crescimento acima da classe I (>Classe I) e abaixo da classe III (<Classe III). Isso foi assim determinado, pois arbitrar classes que agregassem todos os indivíduos criaria amplitudes demasiadamente grandes.

De acordo com a classificação estabelecida, 21 árvores estiveram na classe de crescimento II, na idade de referência. Verifica-se que houve uma dinâmica variada no crescimento das árvores, ou seja, enquanto que 15 árvores permaneceram na mesma classe, 12 mudaram 1 vez de sítio. Salienta-se o desenvolvimento das árvores 6,17 e 21.

As árvores 6 e 21 tiveram incrementos iniciais lentos (sítio abaixo de III), aumentaram (sítio II) e estabilizaram em III. Esses indivíduos possivelmente estavam em áreas pouco propícias, porém com grande cobertura de dossel, e, num dado momento, algum indivíduo vizinho morreu, proporcionando melhores condições, entretanto a concorrência permaneceu alta.

A árvore 17 teve crescimento inicial moderado (com média cobertura de dossel) e seguido de aumento significativo para acima da classe I. Isso provavelmente é decorrente de uma dinâmica de clareira, seja ela natural (decorrente da morte de grandes indivíduos próximos a ela), ou antrópica (em função de abertura de estradas, instalação de rede elétrica, ou outros - fatos constatados por narrativas de moradores locais). $\mathrm{Na}$ fase final da avaliação observou-se uma estabilização do crescimento, mostrando que houve uma recuperação das copas ao seu redor.

De acordo com o modelo de Weibull ajustado não se pode afirmar que a assíntota de crescimento corresponda bem à realidade, pois, utilizando-se árvores com até 70 anos (idade de referência 41 anos), não foi possível determinar o segundo ponto de inflexão, que determina a fase senil da espécie. Em função disso não é válido fazer inferências fora do período de tempo 
SANQUETTA, C.R. et al. Equações individuais e determinação de classes...

analisado. Esse fato decorre da evidência que a espécie é bastante tolerante à sombra, mantendo níveis de crescimento estáveis quando mantidas as condições de sombra, acelerando o crescimento quando alcança o dossel superior. Resultado diferente foi encontrado por Della-Flora et al. (2004), que constataram que Nectandra megapotamica diminui seu incremento com o aumento da concorrência.

A abordagem da classificação das árvores por iluminação de copa usada neste trabalho se assemelha à classificação de sítios usualmente empregada na área florestal (Scolforo, 1993). Embora a analogia entre ambas as abordagens exista, este estudo não se trata de uma classificação de sítios típica. A idéia do mesmo é apresentar curvas que representem o desenvolvimento médio de árvores em diferentes classes, sendo estas possivelmente associadas às condições de iluminação de copa ao longo do tempo. Observa-se ainda que uma árvore pode migrar de uma classe para outra dependendo de alterações ambientais, o que não invalida o método, pelo contrário, propõem uma inovação na análise de crescimento, pois além de considerar a idade também incorpora uma variável ambiental decisiva no desenvolvimento das plantas. Para predizer o DAP de uma árvore crescendo sob sombra e que foi área alvo de abertura de clareira, por exemplo, deve-se considerar que o típico comportamento sigmoidal não mais ocorrerá, ocorrendo um salto abrupto de crescimento representado pela mudança de classe e de curva de crescimento. Obviamente essa reação não será imediata, sendo necessário considerar o tempo necessário para essa passagem de classe.

Outras abordagens para considerar variáveis ambientais no crescimento de árvores, além da idade, vêm sendo propostas (Sanquetta, 1996), porém para indivíduos crescendo em comunidades complexas não é simples retratar a multiplicidade de fatores que ditam os padrões de desenvolvimento (Vanclay, 1983). O método aqui empregado tem suas limitações, como por exemplo a origem dos dados, dificultada pela alta heterogeneidade das características individuais e ambientais do intervalo amostral, e deve ser encarado como uma iniciativa que requer aprofundamento teórico e prático para ter um uso mais amplo na predição do crescimento da espécie em questão.

\section{CONCLUSÕES}

A espécie Nectandra grandiflora forma anéis de crescimento visíveis e com padrão anual, conforme evidenciado pela análise de tronco e comparações com dados de remedições e cintas dendrométricas.

As taxas anuais de crescimento de Nectandra grandiflora são variáveis, conforme pode ser observado nas curvas construídas a partir da análise de tronco. Essas variações ocorrem provavelmente devido a diferenças das condições ambientais onde as árvores se encontram na floresta, principalmente no tocante à iluminação da copas.

Curvas anamórficas construídas a partir do modelo de Weibull caracterizam adequadamente o comportamento heterogêneo do crescimento desta espécie, frente às condições ambientais variáveis, neste caso possivelmente com as diferentes intensidades de iluminação de copa.

\section{AGRADECIMENTOS}

Os autores agradecem gostariam de Desenvolvimento Científico e Tecnológico (CNPq), financiador do Programa de Pesquisas Ecológicas de Longa Duração (PELD), assim como aos vários estudantes de graduação e pós graduação em Engenharia Florestal da UFPR, e outras pessoas atreladas ao Laboratório de Inventário Florestal, pelo auxilio prestado durante as atividades de campo.

\section{REFERÊNCIAS}

1. BERTALANFFY, L. von. Quantitative laws in metabolism and growth. The Quarterly Review of Biology, v. 32, n. 3, p. 217-230, 1957.

2. DELLA-FLORA, J. B.; DURLO, M. A.; SPATHELF, P. Modelo de incremento para árvores singulares - Nectandra megapotamica (Spreng.) Mez. Ciência Florestal, v. 14, n. 1, p. 165-177, 2004.

3. FIGUEIREDO FILHO, A. et al. Avaliação do incremento em diâmetro com o uso de cintas dendrométricas em algumas espécies de uma Floresta Ombrófila Mista localizada no Sul do Estado do Paraná. Revista Ciências Exatas e Naturais, v. 5 , n. 1 , p. $69-84,2003$.

4. FIGUEIREDO FILHO, A. et al. Crescimento sazonal e anual em diâmetro de 16 espécies de uma Floresta Ombrófila Mista na Floresta Nacional de Irati, PR, Brazil. In.: CONGRESSO LATINOAMERICANO IUFRO, 2., 2006, La Serena.Anais... La Serena: IUFRO-INFOR, 2006. v. 1, p. 115-116.

5. GOMPERTZ, B. On the nature of the function expressive of the law of human mortality, and on a new method of determining the value of life contingencies. The Philosophical Transactions of the Royal Society, v. 115, p. 513-583, 1825

6. KORF, V. Příspěvek k matematické definici vzrůstového zákona lesních porostů. Lesnická práce, n. 18, p. 339-379, 1939.

7. LORENZI, H. Árvores brasileiras: manual de identificação e cultivo de plantas arbóreas nativas do Brasil. 2. ed. Nova Odessa: Plantarum, 1998. v. 2, 368 p.

8. MARQUARDT, D. W. An algorithm for least squares estimation of nonlinear parameters. SIAM Journal, v. 11, n. 2, p. 431- 441, 1963.

9. NELDER, J. A. The fitting of a generalization of the logistic curve. Biometrics, v. 17, n. 1, p. 89-110, 1961. 
SANQUETTA, C.R. et al. Equações individuais e determinação de classes...

10. RICHARDS, J. F. A flexible growth function for empirical use. Journal of Experimental Botany, v. 10, n. 2, p. 290-301, 1959

11. SANQUETTA, C. R. Fundamentos biométricos dos modelos de simulação florestal. Curitiba: FUPEF, 1996. 49 p. (Série didática, 08)

12. SANQUETTA, C. R. et al. Estrutura vertical de um fragmento de floresta ombrófila mista no centro sul do Paraná. Revista Floresta, v. 32, n. 2, p. 267-276, 2002.

13. SANQUETTA, C. R.; MATTEI, E. Perspectivas da recuperação e do manejo sustentável das Florestas de Araucária. 1. ed. Curitiba: [autores], 2006. v. 1. 297 p.

14. SCHAAF, L. B. Florística, estrutura e dinâmica no período 1979-2000 de uma Floresta Ombrófila Mista localizada no sul do Paraná. 2001. 118 f. Dissertação (Mestrado em Ciências Florestais) - Setor de Ciências Agrárias, Universidade Federal do Paraná, Curitiba, 2001.

15. SCHAAF, L. B. et al. Incremento diamétrico e em área basal no período 1979-2000 de espécies arbóreas de uma florestal ombrófila mista localizada no sul do Paraná. Revista Floresta, v. 35, n. 2, p. 271-290, 2005.

16. SCOLFORO, J. R. S. Mensuração florestal 4. Classificação de sítios florestais. Lavras: ESAL/FAEPE, 1993.138 p.

17. TONINI, H.; FINGER, C. A. G.; SCHNEIDER, P. R. O crescimento da Nectandra megapotamica Mez., em floresta nativa na depressão central do estado do Rio Grande do Sul. Ciência Rural, v. 33 n. 01, p. 85-90, 2003.

18. VACCARO, S. et al. Incremento em área basal de árvores de uma Floresta Estacional Decidual, em três fases sucessionais, no município de Santa Tereza, RS. Ciência Florestal, v. 13, n. 2, p. 131-142, 2003.

19. VANCLAY, J. K. Techniques for modeling timber yield from indigenous forests with special reference to Queensland. 1983. 194 f. Dissertation (Master of Science in Forestry) - Linacre College, Oxford University, Oxford, 1983

20. WEIBULL, W. A. A statistical distribution function of wide applicability. Journal of Applied Mechanics, v. 18, n. 1, p. 293-297, 1951.

Recebido em 13/08/2008

Aceito em 10/09/2009 